\title{
Suppression of adjuvant disease by bacterial extracellular products
}

\author{
FRANCO QUAGLIATA* AND ANGELO TARANTA
}

From the Rheumatic Diseases Study Group and the Irvington House Institute, Department of Medicine, New York University School of Medicine, 550 First Avenue, New York, N.Y. 10016, U.S.A.

The intradermal injection of a suspension of heatkilled mycobacteria in oil (Freund's adjuvant) produces in the rat a generalized disease, adjuvant arthritis or adjuvant disease (Pearson and Wood, 1959). This can be transferred to syngeneic recipients with lymphoid cells from adjuvant-injected donors but not with serum (Waksman and Wennersten, 1963; Pearson and Wood, 1964a; Quagliata and Phillips-Quagliata, 1972) and is therefore considered to be a manifestation of delayed-type or cellular hypersensitivity to disseminated component(s) of the mycobacterium (Quagliata and Phillips-Quagliata, 1972). In addition, the inflammatory reaction at the site of adjuvant injection provides a useful experimental model for the study of inflammation (Perper, Alvarez, Schroder, and Colombo, 1971).

Antilymphocyte serum (ALS), among its many immunosuppressive properties, has been shown to suppress adjuvant disease (Currey and Ziff, 1968). Another property of ALS is that it stimulates the transformation of lymphocytes into large blast-like cells capable of mitosis (Woodruff, Reid, and James, 1967). Streptococcal culture filtrates have recently been shown to have a similar effect on lymphocytes (Taranta, Cuppari, and Quagliata, 1969; Taranta and Cuppari, 1970); we therefore thought it might be of interest to investigate the effect of such filtrates on adjuvant disease. Cellular components of Gramnegative bacteria have previously been shown to prevent adjuvant disease if injected in incomplete adjuvant, but not in saline, before the eliciting adjuvant injection (Wood and Pearson, 1962).

We report that some preparations of Grampositive as well as Gram-negative bacterial extracellular products injected subcutaneously (s.c.) in saline starting the day before the adjuvant injection markedly suppress adjuvant disease.

\section{Material and methods}

Male Fisher 344 rats $(215-230 \mathrm{~g})$ were obtained from Microbiological Associates, Bethesda, Md, and maintained on a standard pellet and water ration ad libitum.

Adjuvant disease was induced as previously described (Quagliata, Sanders, and Gardner, 1969).

All the rats were weighed immediately before the first injection of the various preparations used and then again as indicated. Bacterial and control preparations were given subcutaneously in $1 \mathrm{ml}$. doses.

The inflammatory reaction in the paws was assessed according to a commonly accepted 4-point scale as? previously described (Quagliata and others, 1969).

Haematocrit, haemoglobin, and red and white blood cell counts, were determined by standard methods.

Differential WBC counts were done after staining with McNeil tetrachrome stain.

The bacterial strains used were Strep. pyogenes (Group A beta-haemolytic streptococcus) M-type 3, T-type 29 (Strain F. Hernandez 7/8/69) originally cultured in this laboratory from a child with pharyngitis; Staph. aureus 4423 No. 75 , S. typhimurium No. 25 , and Strep.pneumoniae R. 36 NC No. 39, obtained from the Department of Microbiology (N.Y.U. School of Medicine).

Each microbial strain was grown overnight in $500 \mathrm{ml}$. of Todd-Hewitt (TH) broth (Difco Labs., Detroit, Michigan), which were then inoculated into $4.5 \mathrm{l}$. of pre-warmed TH broth. After 6 hours' incubation the cultures were centrifuged at $4^{\circ} \mathrm{C}$. for $30 \mathrm{~min}$. at 7,970 G. An aliquot of each bacterial culture was sterilized by filtration through a Nalgene filter (pores $0.2 \mu$ ) and tested for mitogenic activity undiluted and in $1 / 30,1 / 900,1 / 27,000$, and $1 / 810,000$ dilutions on cultures of human peripheral blood lymphocytes; the mitogenic activity was assayed morphologically as previously described (Taranta and others, 1969). The Strep. pyogenes filtrate caused 50 per cent. transformation at an interpolated dilution of 1:500. None of the other bacterial filtrates induced a transformation of 50 per cent. or greater at any of the dilutions tested 
(Taranta and Cuppari, unpublished observation). The supernatants and the uninoculated TH broth used as a control were concentrated by pervaporation at room temperature for $18 \mathrm{hrs}$, dialysed against cold tap-water for $6 \mathrm{hrs}$ and against cold distilled water for $42 \mathrm{hrs}$. The dialysed materials were then re-concentrated by pervaporation at room temperature to a volume of $100 \mathrm{ml}$. and again dialysed in the cold against phosphate-buffered saline for $42 \mathrm{hrs}$. They were then centrifuged at 7,970 G. for $20 \mathrm{~min}$. and filtered through Nalgene filters, after which cultures were negative.

Human serum was obtained from two commercial blood donors. $5 \times$ crystallized ovalbumin (Pentex, Inc., Kankakee, Illinois) was prepared as a $30 \mathrm{mg}$. $/ \mathrm{ml}$. solution.

The protein content of the preparations was determined as tyrosine residues by the Lowry method (Lowry, Rosebrough, Farr, and Randall, 1951) using human gamma globulins (Cohn fraction II) as a standard. The

\section{Results}

\section{FIRST EXPERIMENT}

We tested the effect of two schedules of injections of Strep. pyogenes preparation A on the development of adjuvant disease. Thirty rats were divided into three groups of ten each. The control group was treated with twenty daily injections of $1 \mathrm{ml}$. sterile pyrogenfree 0.9 per cent. sodium chloride (saline), starting the day preceding the adjuvant injection. A second group was injected for the same period with $1 \mathrm{ml}$. of the Strep. pyogenes preparation and a third group was injected with the same preparation for 10 days, starting 4 days after the adjuvant injection. The inflammation score for the three groups was recorded until the 90th day after the adjuvant injection, as indicated in Fig. 1.

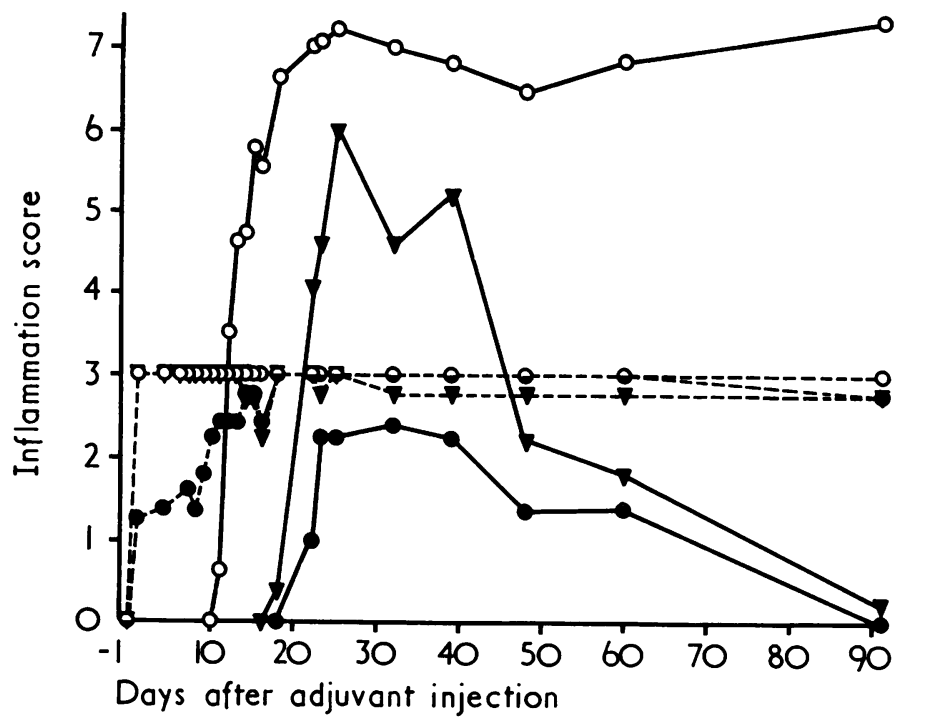

FIG. 1 Inflammation score for the three uninjected paws (solid lines) and for adjuvant-injected hind paw (broken lines) in the saline-treated control group (open circles) and in the groups treated with the Strep. pyogenes preparation for 10 days, starting 4 days after the adjuvant injection (closed triangles), and for 20 days, starting the day before the adjuvant injection (closed circles).

content was as follows:

For Strep. pyogenes preparation A (used for Experiment 1)

For Strep. pyogenes preparation B (used for Experiment 2)

For Strep. pyogenes preparation $\mathrm{C}$ (used for Experiment 3)

For Todd-Hewitt broth, uninoculated

For Staph. aureus preparation

For $S$. typhimurium preparation

For Strep. pneumoniae preparation
The swelling of the adjuvant-injected paw reached a maximum the day after the injection and remained at that level throughout the period of observation in the control group and in the group receiving the Strep. pyogenes preparation starting on Day 4. By contrast, the swelling in the group that received the Strep. pyogenes preparation starting the day before the adjuvant injection was markedly reduced at first, and reached control values only by Day 18 . The reaction in the three uninjected paws was markedly suppressed in both Strep. pyogenes-treated groups, but more so in the group treated for a longer time. In this as in the following experiments there was little variation in the severity of the arthritis among the individual rats of each group. Only the saline-injected rats developed, to a varying degree, the extra-articular manifestations of the disease such as blepharitis, urethritis, and subcutaneous nodules. The Strep. pyogenes-treated rats $-70^{\circ} \mathrm{C}$. until use.

Sheep red blood cells (SRBC) were obtained from the City of New York, Department of Health, Bureau of Laboratories, Otisville Branch, washed three times in sterile saline, and re-suspended to a 10 per cent. suspension for immunization and to a 1 per cent. suspension for haemagglutination determinations, which were carried out as described (Levine and Levytska, 1967). 
Table I Haematological evaluation after a 10- and a 20-day course of Strep. pyogenes preparation (first experiment)*

\begin{tabular}{|c|c|c|c|c|}
\hline \multirow[t]{2}{*}{ Blood cell count } & \multicolumn{2}{|l|}{ After 10 days } & \multicolumn{2}{|l|}{ After 20 days } \\
\hline & Saline & Strep. pyogenes & Saline & Strep. pyogenes \\
\hline $\begin{array}{l}\text { Red } \\
\text { White }\end{array}$ & $\begin{array}{r}5.47( \pm 0 \cdot 19) \times 10^{6} \\
28.5 \quad( \pm 5.59) \times 10^{3}\end{array}$ & $\begin{array}{r}6.65( \pm 0.66) \times 10^{6} \\
22.4( \pm 2 \cdot 85) \times 10^{3}\end{array}$ & $\begin{array}{r}4.38( \pm 0.31) \times 10^{6} \\
27.9 \quad( \pm 5.89) \times 10^{3}\end{array}$ & $\begin{array}{r}5.01( \pm 0.23) \times 10^{6} \\
20.2( \pm 3 \cdot 40) \times 10^{3}\end{array}$ \\
\hline
\end{tabular}

* Mean values ( \pm S.D.)

appeared more active, heavier, and generally healthier throughout the period of observation. The marked leucocytosis and anaemia seen in the controls were considerably reduced in the Strep. pyogenestreated rats (Table I).

\section{SECOND EXPERIMENT}

This was performed to confirm the results of the first with a newly made Strep. pyogenes preparation (preparation B). Ten rats were treated for 20 days, starting the day preceding the adjuvant injection, and ten control rats were concomitantly injected with saline. The joints were scored as before; in addition, weights were also recorded at regular intervals. Photographs of a representative rat of each group are shown in Fig. 2.

As can be seen in Fig. 3 (opposite), preparation B was at least as effective as preparation $\mathbf{A}$ both in delaying the onset of swelling in the injected paw and in suppressing arthritis in the uninjected paws.

Although there was an initial weight loss in both groups, a second phase of weight loss occurred only in the controls, coincident with the appearance of arthritis.

WBC, RBC, and differential counts, determined 21 and 48 days after the adjuvant injection, are given in Table II (opposite). On Day 21 the controls had marked leucocytosis and moderate anaemia as compared to the rats injected with the Strep. pyogenes preparation. By Day 48 the RBC count of the controls had returned to normal, while that of Strep. pyogenes- treated rats was slightly lower. The WBC count had decreased in the controls and in the Strep. pyogenestreated rats-but was definitely lower in the latter. The differential counts were very similar in both groups.

As in the previous experiments, extra-articular manifestations appeared in the controls but not in the rats injected with the Strep. pyogenes preparation, and the general state of health appeared to be better in the latter, as the weight curve clearly shows (Fig. 3).

\section{THIRD EXPERIMENT}

This was designed first to exclude the possibility that the suppression of the disease was merely due to the medium in which the streptococci had been grown, or to antigenic competition, and secondly to investigate the specificity of the phenomenon in terms of the bacterial species involved.

37 rats were divided into eight groups and injected daily for 20 days, starting the day before the adjuvant injection, as follows:

Group 1: Saline.

Group 2: Todd-Hewitt preparation.

Group 3: Human serum.

Group 4: Crystalline ovalbumin.

Group 5: Strep. pyogenes preparation C.

Group 6: Strep. pneumoniae preparation.

Group 7: Staph. aureus preparation.

Group 8: S. typhimurium preparation.

15 days after the adjuvant the rats received $1 \mathrm{ml}$. SRBC intraperitoneally; they were then bled for
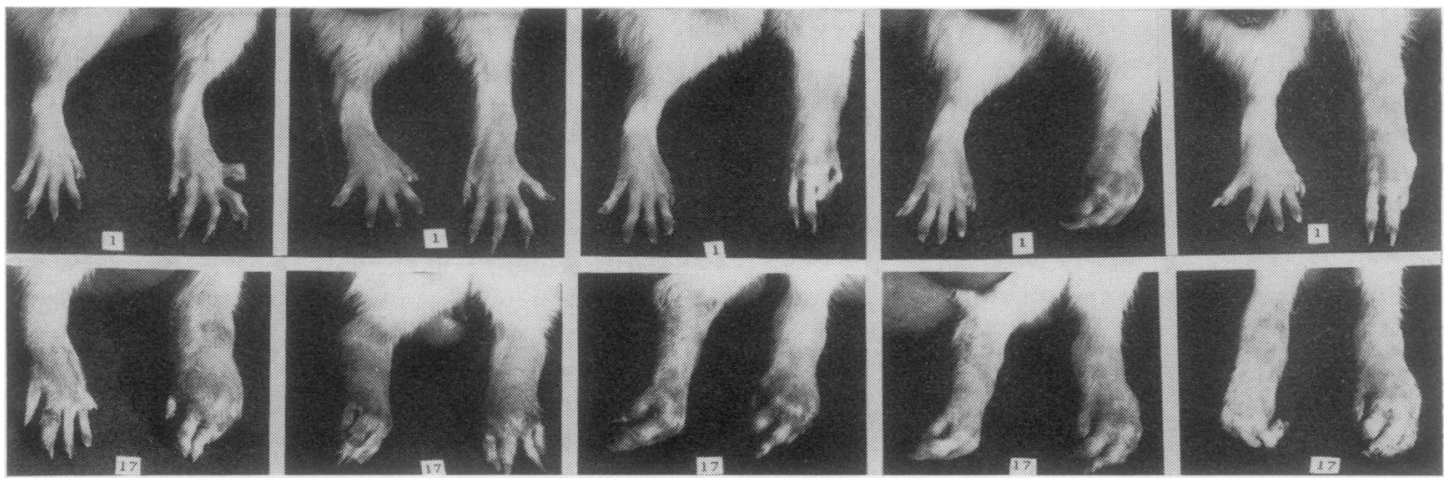

FIG. 2 Hind paws of a Strep. pyogenes treated (No. 1) and a saline treated (No. 17) rat at, from left to right, 14, 21, 31, 45 , and 60 days after adjuvant injection. 


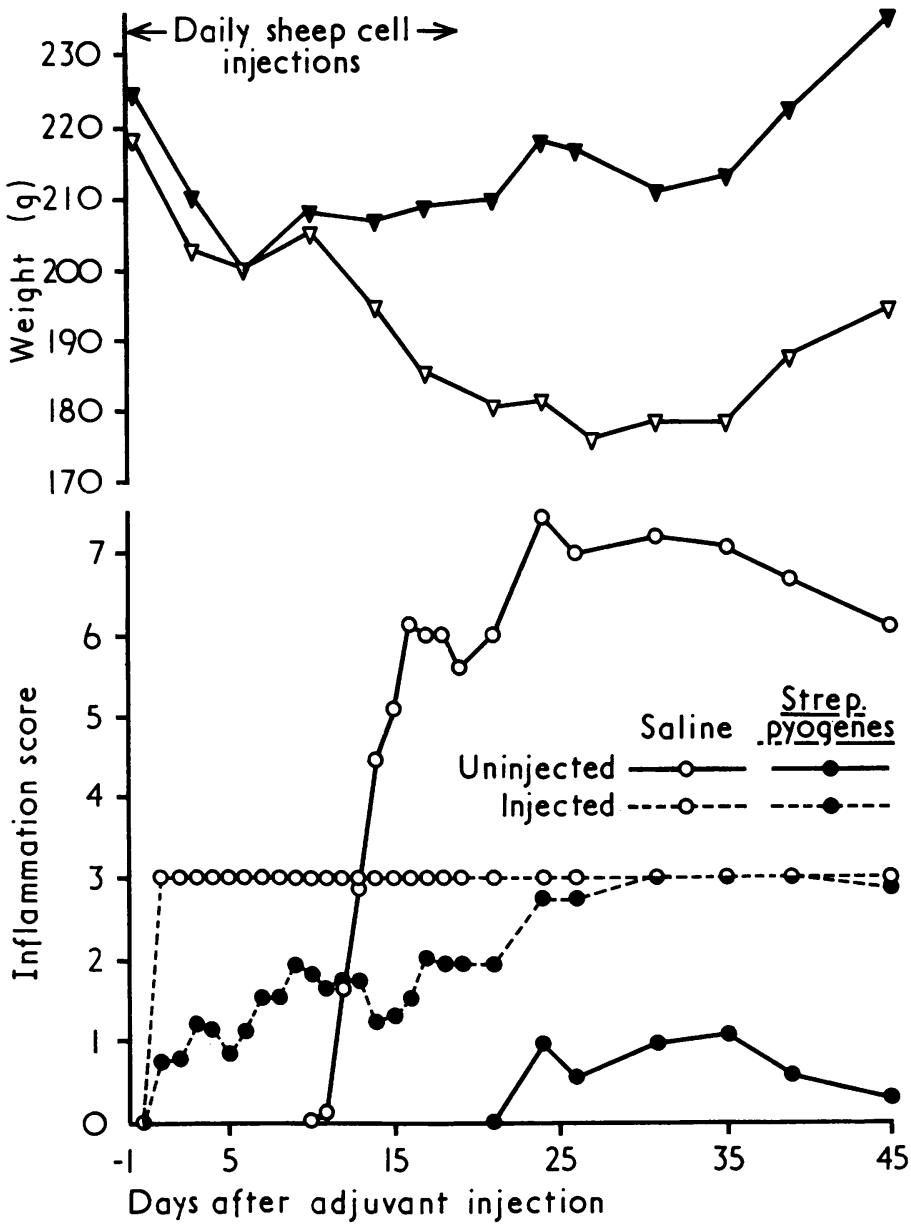

FIG. 3 Weight (triangles, above) and inflammation score (circles, below) in saline-treated (open symbols) and Strep. pyogenes-treated (closed symbols) groups. Inflammation score: solid lines for the three uninjected paws, broken lines for the adjuvant-injected paw.

Table II Haematological evaluation 21 and 48 days after adjuvant injection (second experiment)*

\begin{tabular}{|c|c|c|c|c|}
\hline \multirow{2}{*}{$\begin{array}{l}\text { Days after adjuvant injection } \\
\text { Treatment }\end{array}$} & \multicolumn{2}{|l|}{21} & \multicolumn{2}{|l|}{48} \\
\hline & Saline & Strep. pyogenes & Saline & Strep. pyogenes \\
\hline $\begin{array}{l}\text { Red blood cell count } \\
\text { White blood cell count }\end{array}$ & $\begin{array}{r}5 \cdot 77( \pm 0.88) \times 10^{6} \\
37 \cdot 5( \pm 4.54) \times 10^{3}\end{array}$ & $\begin{array}{r}8.15( \pm 1 \cdot 13) \times 10^{6} \\
22.6( \pm 8.52) \times 10^{3}\end{array}$ & $\begin{array}{r}8.33( \pm 1.42) \times 10^{6} \\
20.5( \pm 3.89) \times 10^{3}\end{array}$ & $\begin{array}{r}8.07( \pm 0.81) \times 10^{6} \\
14.3( \pm 4.49) \times 10^{3}\end{array}$ \\
\hline $\begin{array}{l}\text { Differential: } \\
\text { Mononuclears }\end{array}$ & $39 \cdot 8 \quad \pm 8 \cdot 79$ & $61 \cdot 7 \pm 8.66$ & $49 \cdot 7 \pm 6 \cdot 64$ & $49 \cdot 1 \quad \pm 7 \cdot 50$ \\
\hline $\begin{array}{l}\text { Polys: } \\
\text { Neutrophils } \\
\text { Eosinophils }\end{array}$ & $\begin{aligned} 60 \cdot 1 & \pm 8.62 \\
0 \cdot 1 & \pm 0.45\end{aligned}$ & $\begin{aligned} 37 \cdot 5 & \pm 8 \cdot 52 \\
0.8 & \pm 1 \cdot 24\end{aligned}$ & $\begin{aligned} 50 \cdot 0 & \pm 6.53 \\
0.3 & \pm 0.47\end{aligned}$ & $\begin{aligned} 50 \cdot 1 & \pm 7 \cdot 17 \\
0.8 & \pm 0 \cdot 74\end{aligned}$ \\
\hline
\end{tabular}

* Mean values \pm S.D.

antibody titre determinations 1 and 7 weeks later. Fig. 4 (overleaf) shows the result of this experiment.

In the groups receiving injections of saline or nonbacterial preparations, the swelling of the adjuvant injected paw followed the pattern previously observed in the controls. The swelling of the adjuvant-injected paw was initially decreased in each of the groups of rats receiving preparations of bacterial filtrates. This early local reaction was reduced most markedly in the groups injected with the Strep.pyogenes and with the $S$. typhimurium preparations.

The arthritis in the three uninjected paws was suppressed to a variable extent by the preparations used. Suppression and delay were greatest with the S. typhimurium and the Strep. pyogenes preparations, while the Staph. aureus preparations appeared ineffective. This last preparation caused crusty necrotic lesions at the site of injection. A moderate 

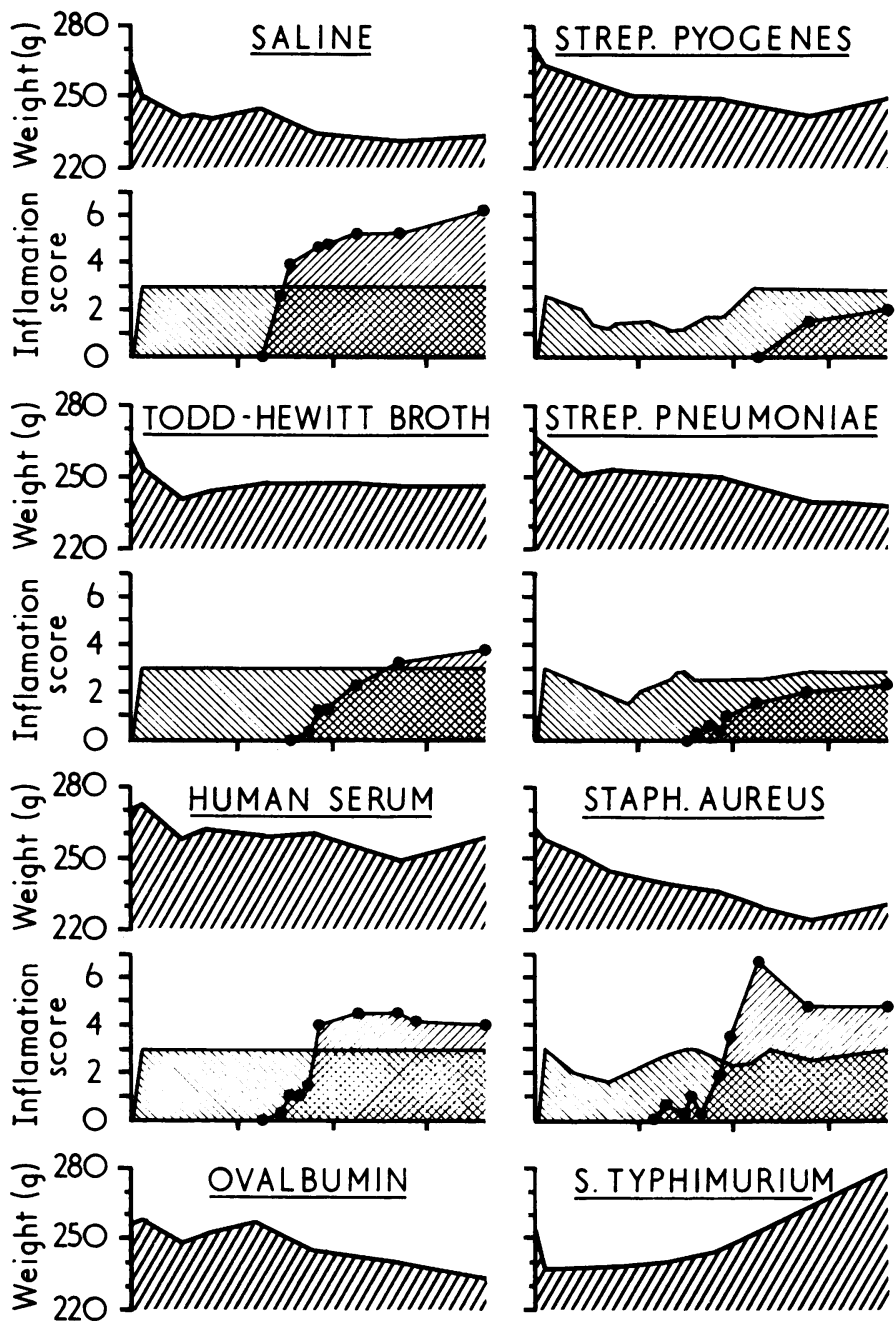

FIG. 4 Weight (hatched areas-top of each panel) and inflammation score (bottom) for the various preparations used for treatment; shaded areas represent score for three uninjected paws, and the line the score for the adjuvant injected paw.

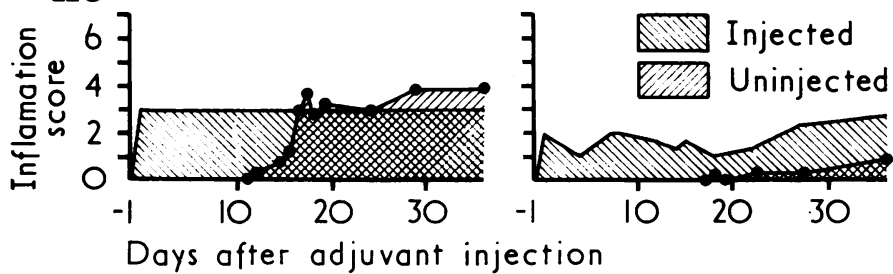

tely anaemic both on Day 21 and Day 49. The other

reduction of the arthritis was achieved also with the non-bacterial preparations.

The weight loss was practically the same in the saline, Staph. aureus, and ovalbumin groups; it was less in the Todd-Hewitt and Strep.pneumoniae groups, and much less in the Strep. pyogenes and human serum groups. The rats injected with $S$. typhimurium preparation, after a sharp initial drop, started gaining weight at an unusually rapid rate.

Haematological observations are shown in Table III (opposite). The saline-treated group was moderagroups were less anaemic, the Strep. pyogenes group being the most normal in this respect.

The WBC counts showed leucocytosis in the saline-injected group and marked leucopenia in the $S$. typhimurium group on Day 21 ; the other groups showed intermediate values. On Day 48 , while most groups had normal values, the $S$. typhimurium group was still definitely leucopenic.

The differential counts showed that the increase in WBC was due mostly to an increase in neutrophils, 
Table III Haematological evaluation 21 and 49 days after adjuvant injection (third experiment)*

\begin{tabular}{|c|c|c|c|c|c|c|c|c|c|}
\hline Day & & Saline & $\begin{array}{l}\text { Todd- } \\
\text { Hewitt }\end{array}$ & $\begin{array}{l}\text { Human } \\
\text { serum }\end{array}$ & $\begin{array}{l}\text { Cryst. } \\
\text { ovalbumin }\end{array}$ & $\begin{array}{l}\text { Strep. } \\
\text { pyogenes }\end{array}$ & $\begin{array}{l}\text { Strep. } \\
\text { pneum. }\end{array}$ & $\begin{array}{l}\text { Staph. } \\
\text { aureus }\end{array}$ & $\begin{array}{l}\text { S. } \\
\text { typhim. }\end{array}$ \\
\hline 21 & $\begin{array}{l}\text { Hct } \\
\mathrm{Hb} \\
\mathrm{RBC} \dagger \\
\text { WBC } \dagger \\
\text { Neut. } \\
\text { Eosin. } \\
\text { Mono. }\end{array}$ & $\begin{array}{l}39 \cdot 0 \\
\pm 2 \cdot 50 \\
12.0 \\
\pm 0.38 \\
6 \cdot 59 \times 10^{6} \\
\pm 0 \cdot 27 \\
31 \cdot 2 \times 10^{3} \\
\pm 5 \cdot 41 \\
67 \cdot 2 \\
\pm 7 \cdot 6 \\
0 \cdot 8 \\
\pm 0 \cdot 63 \\
32 \cdot 0 \\
\pm 7 \cdot 04\end{array}$ & $\begin{array}{l}48 \cdot 1 \\
\pm 2 \cdot 09 \\
14 \cdot 5 \\
\pm 0 \cdot 20 \\
7 \cdot 35 \times 10^{6} \\
\pm 0 \cdot 67 \\
19 \times 10^{3} \\
\pm 8 \cdot 34 \\
52 \cdot 0 \\
\pm 1 \cdot 63 \\
1 \cdot 0 \\
\pm 0 \cdot 81 \\
47 \cdot 0 \\
\pm 1 \cdot 41\end{array}$ & $\begin{array}{l}39 \cdot 5 \\
\pm 5 \cdot 18 \\
12 \cdot 8 \\
\pm 1 \cdot 6 \\
6 \cdot 5 \times 10^{6} \\
\pm 0 \cdot 44 \\
15 \cdot 25 \pm 10^{3} \\
\pm 2 \cdot 16 \\
52 \cdot 5 \\
\pm 6 \cdot 10 \\
2 \cdot 0 \\
\pm 2 \cdot 44 \\
45 \cdot 5 \\
\pm 4 \cdot 27\end{array}$ & $\begin{array}{l}4 \cdot 2 \\
\pm 3 \cdot 26 \\
14 \\
\pm 1 \cdot 18 \\
7 \cdot 11 \pm 10^{6} \\
\pm 0 \cdot 80 \\
23 \cdot 75 \times 10^{3} \\
\pm 5 \cdot 80 \\
61 \cdot 0 \\
\pm 12 \cdot 88 \\
1 \cdot 5 \\
\pm 0 \cdot 86 \\
37 \cdot 5 \\
\pm 12 \cdot 11\end{array}$ & $\begin{array}{l}48 \cdot 6 \\
\pm 3 \cdot 06 \\
14 \cdot 7 \\
\pm 0 \cdot 68 \\
7 \cdot 8 \times 10^{6} \\
\pm 1 \cdot 02 \\
23 \times 10^{3} \\
\pm 1 \cdot 22 \\
50 \cdot 25 \\
\pm 15 \cdot 28 \\
0 \cdot 25 \\
\pm 0 \cdot 43 \\
49 \cdot 5 \\
\pm 15 \cdot 58\end{array}$ & $\begin{array}{l}46.0 \\
\pm 0.94 \\
14 \cdot 7 \\
\pm 0.44 \\
6 \cdot 89 \times 10^{6} \\
\pm 1 \cdot 50 \\
14.8 \times 10^{3} \\
\pm 1 \cdot 72 \\
55 \cdot 0 \\
\pm 7 \cdot 23 \\
0 \cdot 8 \\
\pm 0 \cdot 74 \\
44 \cdot 2 \\
\pm 7.08\end{array}$ & $\begin{array}{l}44 \cdot 3 \\
\pm 1 \cdot 20 \\
13 \cdot 7 \\
\pm 0 \cdot 29 \\
6 \cdot 89 \times 10^{6} \\
\pm 0 \cdot 70 \\
27 \pm 10^{3} \\
\pm 4 \cdot 14 \\
61 \cdot 0 \\
\pm 17 \cdot 53 \\
1 \cdot 4 \\
\pm 1 \cdot 49 \\
37 \cdot 6 \\
\pm 17 \cdot 36\end{array}$ & $\begin{array}{l}42.9 \\
\pm 1.51 \\
13.8 \\
\pm 0.55 \\
6.48 \times 10^{6} \\
\pm 0.58 \\
8.25 \times 10^{3} \\
\pm 0.82 \\
47.75 \\
\pm 7.75 \\
1.25 \\
\pm 1.29 \\
51.0 \\
\pm 9.02\end{array}$ \\
\hline 49 & $\begin{array}{l}\text { Hct } \\
\mathrm{Hb} \\
\mathrm{RBC} \dagger \\
\mathrm{WBC} \dagger \\
\text { Neut. } \\
\text { Eosin. } \\
\text { Mono. }\end{array}$ & $\begin{array}{l}40 \cdot 6 \\
\pm 3 \cdot 47 \\
11 \cdot 3 \\
\pm 1 \cdot 96 \\
6 \cdot 8 \times 10^{6} \\
\pm 0 \cdot 59 \\
19 \times 10^{3} \\
\pm 5 \cdot 43 \\
34 \cdot 0 \\
\pm 7 \cdot 78 \\
2 \cdot 0 \\
\pm 0 \cdot 81 \\
64 \cdot 0 \\
\pm 8 \cdot 52\end{array}$ & $\begin{array}{l}43 \cdot 8 \\
\pm 9 \cdot 07 \\
12 \cdot 8 \\
\pm 1 \cdot 62 \\
7 \cdot 1 \times 10^{6} \\
\pm 0 \cdot 32 \\
16 \times 10^{3} \\
\pm 4 \cdot 32 \\
45 \cdot 66 \\
\pm 5 \cdot 43 \\
1 \cdot 0 \\
\pm 0 \cdot 70 \\
53 \cdot 3 \\
\pm 4 \cdot 71\end{array}$ & $\begin{array}{l}49 \cdot 5 \\
\pm 2 \cdot 12 \\
14 \cdot 3 \\
\pm 0 \cdot 46 \\
8 \cdot 3 \times 10^{6} \\
\pm 0 \cdot 16 \\
21 \cdot 5 \times 10^{3} \\
\pm 3 \cdot 04 \\
49 \cdot 75 \\
\pm 13 \cdot 40 \\
2 \cdot 25 \\
\pm 1 \cdot 29 \\
48 \cdot 0 \\
\pm 3 \cdot 24\end{array}$ & $\begin{array}{l}41 \cdot 0 \\
\pm 6.43 \\
11.4 \\
\pm 2 \cdot 09 \\
6 \cdot 7 \times 10^{6} \\
\pm 0 \cdot 54 \\
36 \times 10^{3} \\
\pm 14.50 \\
59 \cdot 5 \\
\pm 6 \cdot 87 \\
0 \cdot 75 \\
\pm 0.43 \\
39.75 \\
\pm 8.95\end{array}$ & $\begin{array}{l}47 \cdot 0 \\
\pm 2 \cdot 50 \\
13 \cdot 6 \\
\pm 1 \cdot 09 \\
8 \cdot 2 \times 10^{6} \\
\pm 0 \cdot 28 \\
14 \times 10^{3} \\
\pm 2 \cdot 44 \\
37 \cdot 0 \\
\pm 6 \cdot 08 \\
1 \cdot 75 \\
\pm 1 \cdot 92 \\
61 \cdot 25 \\
\pm 7 \cdot 56\end{array}$ & $\begin{array}{l}44 \cdot 5 \\
\pm 6 \cdot 41 \\
12 \cdot 0 \\
\pm 1 \cdot 88 \\
7 \cdot 0 \times 10^{6} \\
\pm 0 \cdot 83 \\
13 \times 10^{3} \\
\pm 0 \cdot 81 \\
47 \cdot 0 \\
\pm 6 \cdot 48 \\
2 \cdot 33 \\
\pm 0 \cdot 94 \\
50 \cdot 66 \\
\pm 5.90\end{array}$ & $\begin{array}{l}45 \cdot 6 \\
\pm 6 \cdot 17 \\
13 \cdot 2 \\
\pm 1 \cdot 33 \\
7 \cdot 9 \pm 10^{6} \\
\pm 0 \cdot 50 \\
21 \cdot 2 \times 10^{3} \\
\pm 4 \cdot 16 \\
33 \cdot 6 \\
\pm 10 \cdot 44 \\
1 \cdot 2 \cdot 1 \\
\pm 1 \cdot 16 \\
65 \cdot 5 \\
\pm 11.67\end{array}$ & $\begin{array}{l}47 \cdot 6 \\
\pm 0 \cdot 73 \\
12 \cdot 9 \\
\pm 0 \cdot 72 \\
7 \cdot 3 \times 10^{6} \\
\pm 0 \cdot 53 \\
7 \times 10^{3} \\
\pm 1 \cdot 87 \\
47 \cdot 0 \\
\pm 8 \cdot 54 \\
0 \cdot 25 \\
\pm 0 \cdot 43 \\
52 \cdot 75 \\
\pm 8 \cdot 16\end{array}$ \\
\hline
\end{tabular}

* Mean values ( \pm S.D.).

$\dagger$ Pre-treatment values were: $\mathrm{RBC}=8 \cdot 1 \times 10^{6} ; \mathrm{WBC}=13.8 \times 10^{3}$.

which was particularly marked at Day 21 in the saline, ovalbumin, and Staph. aureus groups and at Day 49 in the ovalbumin group.

Table IV summarizes the haemagglutination data. One week after immunization with SRBC, the only significant reduction in the anti-SRBC titre, as compared with the saline-treated controls, was observed in the group treated with the $S$. typhimurium

Table IV Agglutination titres* against sheep red blood cells in rats treated with preparations of bacterial extracellular products or control preparations

\begin{tabular}{|c|c|c|}
\hline \multirow[t]{2}{*}{$\begin{array}{l}20 \text { days treatment } \\
\text { with }\end{array}$} & \multicolumn{2}{|c|}{$\begin{array}{l}\text { Time after immunization with } \\
\text { sheep red blood cells } \dagger\end{array}$} \\
\hline & 1 week & 6 weeks \\
\hline $\begin{array}{l}\text { Saline } \\
\text { Todd-Hewitt } \\
\text { Human serum } \\
\text { Crystalline ovalbumin } \\
\text { Strep. pyogenes } \\
\text { Strep. pneumoniae } \\
\text { Staph. aureus } \\
\text { S. typhimurium }\end{array}$ & $\begin{array}{r}12 \cdot 72 \pm 1 \cdot 62 \\
12 \cdot 32 \pm 0 \cdot 81 \\
10 \cdot 82 \pm 1 \cdot 11 \\
13 \cdot 57 \pm 1 \cdot 29 \\
12 \cdot 82 \pm 0 \cdot 86 \\
12 \cdot 52 \pm 0.74 \\
11 \cdot 52 \pm 2 \cdot 31 \\
9 \cdot 57 \pm 0 \cdot 82 \ddagger\end{array}$ & $\begin{array}{l}11 \cdot 98 \pm 1 \cdot 69 \\
10 \cdot 98 \pm 1 \cdot 24 \\
12 \cdot 07 \pm 2 \cdot 16 \\
15 \cdot 32 \pm 0.00 \\
12 \cdot 92 \pm 1 \cdot 20 \\
12 \cdot 32 \pm 1 \cdot 00 \\
11 \cdot 52 \pm 1 \cdot 72 \\
11 \cdot 82 \pm 0.50\end{array}$ \\
\hline
\end{tabular}

* Mean $\log _{2}$ titre \pm standard deviation.

† All rats were immunized with sheep red blood cells 2 weeks after the injection of adjuvant and the beginning of treatment with the various preparations.

$\ddagger$ Significantly lower than saline-injected control group $(P<0.05)$, Student's t-test. preparation. 6 weeks after immunization no significant differences were observed.

\section{Discussion}

The development of adjuvant disease presumably depends on the integrity of both immunological and inflammatory mechanisms. Predominantly antiinflammatory drugs, such as cortisone, suppress the manifestations of the disease for as long as they are administered, but shortly after their administration is stopped the disease manifests itself (Newbould, 1963). Immunosuppressive agents, on the other hand, may suppress the disease permanently (reviewed by Quagliata and others, 1969). The local reaction which occurs soon after the adjuvant injection depends mainly on inflammatory mechanisms (Perper and others, 1971). The suppression of adjuvant disease, particularly with the Strep. pyogenes and $S$. typhimurium preparations, appeared to affect both inflammatory and immune responses: the local early reaction at the site of the adjuvant injection was decreased, and the arthritis in the uninjected paws was not only delayed but suppressed, i.e. its intensity was decreased if and when it appeared.

It is probable that the mechanisms involved in the suppression of adjuvant arthritis are not the same for 
the preparations of extracellular products of Grampositive and Gram-negative bacteria. Only the rats injected with the Gram-negative bacterial preparation developed a marked leucopenia (see Table III); this could well have interfered with the inflammatory and the immune response.

That micro-organisms may produce substances which interfere with the inflammatory response is not, of course, a novel idea. Levaditi (1918) may have been the first to report an in vitro correlate of this interference-the ability of some streptococcal strains to kill leucocytes when engulfed by them. With a few exceptions (Malakian and Schwab, 1968, 1971; Hanna and Watson, 1968), the ability of micro-organisms to interfere with immune mechanisms does not appear to have been studied, although both streptococci and staphylococci are known to produce substances capable of reacting with human lymphocytes (Taranta and others, 1969; Ling, Spicer, James, and Williamson, 1965). Immunosuppression with a streptococcal preparation which differs from ours in being of cellular rather than extracellular origin (Malakian and Schwab, 1968, 1971) has been reported. Immunosuppression with preparations of streptococcal pyrogenic exotoxin (Hanna and Watson, 1968) has also been reported. Whether this toxin is the mediator of the effect we have described remains to be determined as far as the Strep. pyogenes preparations are concerned. It cannot, of course, be the mediator of the effect observed with the Strep. pneumoniae or S. typhimurium preparations, since neither of these organisms is known to produce streptococcal pyrogenic exotoxin or any toxin closely related to it.

The possibility that the inhibitory effect of the Strep. pyogenes preparations might be due to the streptococcal mitogen known to be present in them (Taranta and others, 1969; Taranta and Cuppari, 1970) deserves consideration, since other substances capable of inducing lymphocyte transformation, notably ALS, are immunosuppressive. Again, however, the arthritis inhibitory effect of the Strep. pneumoniae and $S$. typhimurium preparations cannot be explained on this basis, since these species are known not to produce extracellular substances comparable to the streptococcal and staphylococcal mitogens (Taranta and Cuppari, 1970) and the particular strains tested were not exceptions (Taranta and Cuppari, unpublished observations).

The possibility that the suppression of adjuvant disease by extracellular bacterial products is the result of antigenic competition (Wood and Pearson, 1962; Gery and Waksman, 1967; Pearson and Wood, 1964b) was considered: therefore two additional controls were included in the third experiment, one (crystalline ovalbumin) consisting essentially of a single protein and the other (human serum) consisting of about as many proteins as are present in the Strep. pyogenes culture filtrate. Neither of these control preparations provided a reduction of the disease of the degree obtained with the active bacterial products-thus failing to support the hypothesis of antigenic competition as the only or main mechanism of the suppression of adjuvant disease obtained with the bacterial products.

It should be noted that the maximum suppression obtained (in S. typhimurium and Strep. pyogenestreated rats) was quantitatively similar to that reported by others and by one of us with ALS and other powerful disruptors of immune mechanisms (Currey and Ziff, 1968; Quagliata and others, 1969; Quagliata, Phillips-Quagliata, and Floersheim, 1972; Zurier and Quagliata, 1971). Therefore, further study of this suppression and definition of the extracellular bacterial products involved may be rewarding in terms of experimental pathology and therapeutics.

\section{Summary}

Both the inflammatory response at the site of adjuvant injection and the subsequent development of adjuvant disease in the rat were markedly suppressed by the administration of extracellular products from some bacterial species. Salmonella typhimurium products caused marked leucopenia, inhibition of circulating antibody response, and suppression of adjuvant disease. Strep. pyogenes products did not cause leucopenia or inhibition of circulating antibody response, yet they caused marked inhibition of adjuvant disease. Strep. pneumoniae products had similar, but less marked effects, while Staph. aureus products were ineffective.

\section{References}

CurRey, H. L. F. AND ZifF, M. (1968) J. exp. Med., 127, 185 (Suppression of adjuvant disease in the rat by heterologous antilymphocyte globulin)

Gery, I., AND WaKSMAN, B. H. (1967) Arthr. and Rheum. 10, 240 (Competition of antigens in adjuvant disease of rats)

HANNA, E. E., AND WATSON, D. W. (1968) J. Bact., 95, 14 (Host-parasite relationship among group A streptococci. IV. Suppression of antibody response by streptococcal pyrogenic exotoxin)

LeVAdIT, C. (1918) Ct. R. Soc. Biol., 81, 1064 (Action leukotoxique du streptocoque des plaies de guerre. Considerations sur le mechanisme de la phagocytose)

LEVINE, B. B., AND LEVYTSKA, V. (1967) J. Immunol., 98, 648 (A sensitive hemagglutination assay method for dinitrophenyl-specific antibodies. The effect of antibody binding affinity on titers) 
Ling, N. R., SPicer, E., James, K., AND Williamson, N. (1965) Brit. J. Haemat., 11, 421 (The activation of human peripheral lymphocytes by products of staphylococci)

Lowry, O. H., Rosebrough, N. J., Farr, A. L., AND Randall, R. J. (1951). J. biol. Chem., 193, 265 (Protein measurement with the Folin phenol reagent)

Malakian, A., AND SchWAB, J. H. (1968) Science, 159, 880 (Immunosuppressant from group A streptococci) (1971) J. exp. Med., 134, 1253 (Biological characterization of an immunosuppressant from group A streptococci)

Newbould, B. B. (1963). Brit. J. Pharmacol., 21, 127 (Chemotherapy of arthritis induced in rats by mycobacterial adjuvant)

Pearson, C. M., AND Wood, F. D. (1959) Arthr. and Rheum. 2, 440 (Studies of polyarthritis and other lesions induced in rats by injection of mycobacterial adjuvant. I. General clinical and pathologic characteristics and some modifying factors)

_ - (1964a). J. exp. Med. 120, 547 (Passive transfer of adjuvant arthritis by lymph node or spleen cells) (1964b) Arthr. and Rheum., 7, 337 (Inhibition of adjuvant arthritis by some protein antigens)

Perper, R., Alvarez, B., Schroder, H., AND Colombo, C. (1971) Fed. Proc., 30, 386 (Adjuvant arthritis: A model to separate anti-inflammatory from immunosuppressive agents)

Quagliata, F., AND Phillips-Quagliata, J. M. (1972) Cell. Immunol., 3, 78 (Competence of thoracic duct cells in the transfer of adjuvant disease and delayed hypersensitivity. Evidence that mycobacterial components are required for the successful transfer of the disease)

AND FlOERSHEIM, G. L. (1972) Ibid., 3, 198 (Immunosuppression by procarbazine. I. Site of action of the drug and effect on adjuvant arthritis and circulating antibody responses)

- SANDers, P. M., AND Gardner, D. L. (1969) Ann. rheum. Dis., 28, 163 (Suppression of adjuvant arthritis by a new cytoxic compound, Rubidomycin)

Taranta, A., AND Cuppari, G. (1970) Circulation, 41-42, Suppl. 3, 103 (Streptococcal mitogen, an extracellular product seemingly specific of group A) (Abstract No. 372) (Unpublished observations) AND QUaGliata, F. (1969) J. exp. Med., 129, 605 (Dissociation of hemolytic and lymphocyte transforming activities of streptolysin $\mathrm{S}$ preparations)

Waksman, B. H., AND Wennersten, C. (1963) Int. Arch. Allerg., 23, 129 (Passive transfer of adjuvant arthritis in rats with living lymphoid cells of sensitized donors)

Wood, F. D., AND Pearson, C. M. (1962) Science, 137, 544 (Protection of rats against adjuvant arthritis by bacterial lipopolysaccharides)

WoODRUFF, M. F. A., REID, B., AND JAMES, K. (1967) Nature (Lond.), 215, 591 (Effect of antilymphocytic antibody and antibody fragments on human lymphocytes in vitro)

ZuRIER, R. B., AND QUagliatA, F. (1971) Ibid., 234, 304 (Effect of Prostaglandin $E_{1}$ on adjuvant arthritis) 